\title{
Illusion of Control in Internet Users and College Students
}

\author{
HELENA MATUTE, Ph.D., MIGUEL A. VADILLO, Ph.D., SONIA VEGAS, Ph.D., \\ and FERNANDO BLANCO, B.A.
}

\begin{abstract}
When people try to obtain a desired event and this outcome occurs independently of their behavior, they often think that they are controlling its occurrence. This is known as the illusion of control, and it is the basis for most superstitions and pseudosciences. However, most experiments demonstrating this effect had been conducted many years ago and almost always in the controlled environment of the psychology laboratory and with psychology students as subjects. Here, we explore the generality of this effect and show that it is still today a robust phenomenon that can be observed even in the context of a very simple computer program that users try to control (and believe that they are controlling) over the Internet. Understanding how robust and general this effect is, is a first step towards eradicating irrational and pseudoscientific thinking.
\end{abstract}

\section{INTRODUCTION}

$\mathbf{T}$ HE ILLUSION OF CONTROL refers to the tendency that people have to believe that desired events that occur when they are trying to obtain them are caused by their own behavior. ${ }^{1}$ Indeed, the existence of this effect should not be surprising if we think about the history of humankind and about the many times that humans have developed superstitious behaviors that made them believe that they were controlling important events, such as rain or even their own health. More surprising should be to know that the illusion of control is still today a robust phenomenon and that it can be observed even through the Internet.

This illusion can sometimes be adaptive (as when it protects people from detecting that important outcomes are uncontrollable, which in turn may protect them from depression ${ }^{2,3}$ ) but it can also be quite maladaptive (as when the illusion that a given ritual controls an illness prevents a patient from going to the hospital). Thus, it is important to know whether this is today just a laboratory artefact or is, by contrast, a general and extended effect.

There have been proposed many different ways to assess the degree of objective contingency (or control) that exists between a participant's behavior and a given outcome. Perhaps the most generally accepted measurement of contingency is $\triangle \mathrm{P}^{4}$ which is the difference between the probability of the outcome occurring when the response is emitted and the probability of the outcomes occurring when the response is not emitted. That is, $\triangle \mathrm{P}=\mathrm{p}(\mathrm{O} \mid \mathrm{R})-$ $\mathrm{p}(\mathrm{O} \mid$ noR $)$. When an outcome is uncontrollable both probabilities are identical and $\triangle \mathrm{P}$ equals $\geq$ zero. Overestimation of control occurs when the outcome is desired and occurs frequently, or when it is aversive and occurs rarely. $2,5,6$

The illusion of control has been demonstrated in a wide variety of situations. ${ }^{1,2,5,7}$ For example, Matute ${ }^{3,8}$ used a very simple computer program that presented aversive noises. The participants were

Department of Psychology, University of Deusto, Bilbao, Spain. 
motivated through instructions to terminate the noises, but the duration of each noise had been preprogrammed and there was nothing that the participants could do to control them. However, participants did not realize that their responses were ineffective. According to Matute, participants kept typing something each time that the noise was presented and, in consequence, every time that the noise finished the participants had no way of knowing that the noise would have also finished if they had done nothing. When asked at the end of the experiment to what degree they believed they had had control over noise termination, they showed a considerable illusion of control.

And, as previously mentioned, this is true also for the opposite condition in which the participant is trying to avoid an unpleasant event by refraining to perform a given action and the unpleasant event does not occur or occurs rarely. ${ }^{5}$ Note that, in this case, the "no action" is actually another form of action, and that, in both cases, the response (whether active or passive) is followed by a frequent reinforcer (or an infrequent aversive event). This is like people following bizarre rituals or pseudo-therapies to improve their health: as long as they feel fine, they will attribute their good health to the ritual they performed.

Perhaps the simpler explanation that can be proposed to account for superstitious behaviours and illusions of control is that, because people trying to obtain something tend to respond as much as they can, if the outcome is relatively frequent it will generally tend to occur in the presence of responding. 8,9 Therefore, the actual contiguity between response and outcome is there, even though it is spurious. Indeed, the results of Matute ${ }^{8}$ showed that participants exposed to frequent uncontrollable reinforcers tended to respond in almost every trial, which increased the chances that adventitious response-outcome pairings occur. In order to learn that the outcome does not depend on their behavior participants should act only in $50 \%$ of the trials, so that they could be exposed both to the probability of the outcome occurring when they perform the response as well as to the probability of the outcome occurring when they do not respond. However, this is something that most people are unwilling to test on their own. Just as most people trying to avoid bad luck by not taking room number 13 in a hotel would not risk the more scientific strategy of testing what the probability of the outcome would be if they took room 13, experimental participants do not test by default what the probability of noise termination would be if they do nothing. However, when participants are explicitly requested to respond in $50 \%$ of the trials, they realize that their behavior does not affect the probability of the outcome. ${ }^{8,10,11}$ Figure 1 illustrates this process.

In addition to this explanation based on the subjects' high tendency to act when they are trying to obtain something, ${ }^{8}$ many other different explanations have also been proposed to account for the illusion of control. Most of these explanations assume that personality and internal variables are responsible for the effect. These include attributional styles, locus of control, depression, negativity, self-efficacy beliefs, response-outcome expectations, among others. ${ }^{1,2,12,13,14}$ Most probably, these theoretical approaches are all partly right and all of these factors do contribute to some degree to the development of the illusion of control. The purpose of the present research is not to discriminate among them. Instead, we believe that what is of most importance at present is to assess the generality of the effect.

Despite the apparent robustness of the published results on the illusion of control, it is easy to argue that experimental data on the illusion of

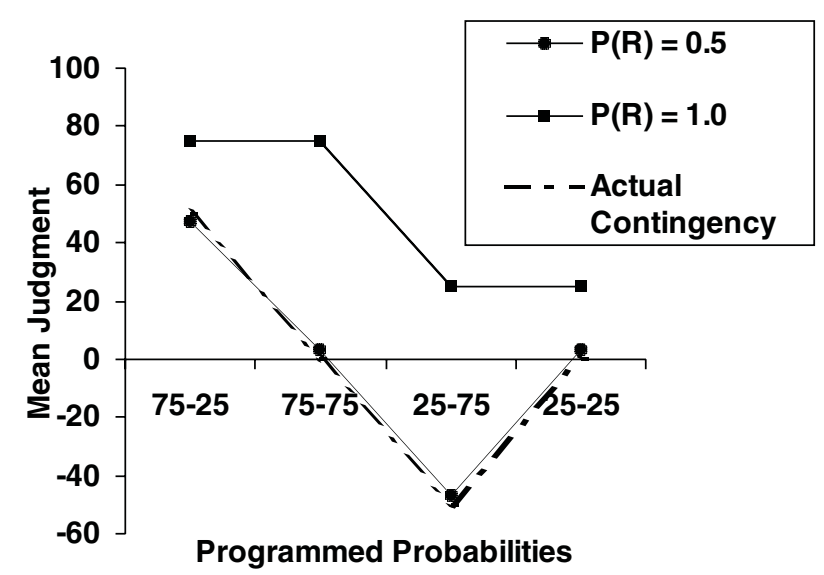

FIG. 1. Simulation of fictitious subjects responding either in $50 \%$ of the trials, $p(\mathrm{R})=0.5$, or in every trial, $p(\mathrm{R})=1$. Four different conditions were run: 75-75, $75-25,25-75$, and 25-25 (the first number represents the probability of the outcome in the presence of responding; the second number represents the probability of the outcome in the absence of responding; the difference between those two numbers represents the objective contingency or $\triangle \mathrm{P})$. For all conditions, subjects responding with a $p(\mathrm{R})=0.5$ produce judgments that are more similar to the actual contingency than subjects responding with a $p(R)$ of 1 . This result can be obtained using different implementations of generally accepted learning models such as, for example, the Rescorla-Wagner ${ }^{19}$ model. A simple calculation of the $\triangle \mathrm{P}$ contingency index ${ }^{4}$ produces the same result as well (for calculation purposes, the high $p(\mathrm{R})$ example can be set to 0.99999 rather than 1 ). 
control were somewhat artificial and laboratorydependent. As an example, it could well be that the effect occurred because many of those experiments were conducted many years ago and made use of computers and other automated devices with which the regular student-participant was not familiar at the time. Today's college students, who are used to work with computers at all times, should not generate the same illusion of control in such a simple preparation as that used for previous experiments. Additionally, it is also possible that, because most participants in previous experiments had been psychology students, the results might not apply to a more general population. The purpose of the present research was therefore to assess whether the illusion of control is still today a reliable phenomenon and whether it can be observed outside of the psychology laboratory. To this end we used the Internet as our testing arena in order to best assess the generality and reliability of this effect.

\section{METHODS}

\section{Participants}

Our Internet participants $(n=92)$ were anonymous voluntaries who visited our virtual laboratory (www.labpsico.com) and decided to take part in the experiment. In order to comply with ethical guidelines for human research through the Internet ${ }^{15}$ and to assure that all participants were both anonymous and voluntary, we decided not to request any personal data, nor did we use cookies or software to obtain involuntary information from the participants. Thus, they are of any age, sex, country, or other personal conditions. We controlled for the potential problem of getting noisy data over the Internet by performing an exact replication with anonymous and voluntary psychology students that conducted the experiment in our laboratory $(n=98)$. In both cases, the computer program randomly assigned each participant to each of the experimental conditions that we describe below. ${ }^{16,17}$

\section{Procedure}

The procedure replicated a previous study ${ }^{8}$ except that, in order to facilitate its execution over the Internet, the participants were requested to control visual images (blue flashes) in the computer screen rather than noises. All flashes had a fixed duration of 1 second, but there were two types of trials, which were presented in random order. In $75 \%$ of the trials, the flashes were programmed to appear very rapidly (within 1 second), which means that, in $75 \%$ of the trials, the response (or the non-response) was immediately followed by the occurrence of a flash. In the other $25 \%$ of trials, the flashes did not appear until 5 seconds had elapsed, which means that the response-or the nonresponse-was generally not followed by a flash (or at least not immediately). This was done in this way because a high probability of reinforcer is known to favor the illusion of control. ${ }^{2,6,12}$

However, we manipulated the instructions and the post-experimental assessment questions as a means to reduce the illusion of control in some of the conditions. Half of the participants in each location were simply requested to control the flashes that appeared on the screen (this is the standard illusion of control condition); the other half was warned that they might have no control over the occurrence of the flashes (presumably, these participants should show no illusion of control). Orthogonally, half of the participants in each of those groups was told that their task was to obtain the flashes (this is the standard illusion of control condition, in which the event that occurs frequently is the one that the participant is trying to obtain); the other half was told that their task was to avoid the occurrence of the flashes (this is the opposite condition, as if one takes herbs to avoid headaches but keeps suffering from headaches every three out of four days).

After 50 trials in which participants tried to control the flashes, they were asked two successive questions about the degree of control that they believed they had had over the flashes. The first question was neutral; the second one was very explicitly worded so as to reduce the illusion of control (Fig. 2). To introduce their response participants could click any point in a 0-100 rating scale that was located just below each question. The scale was anchored at 0 and 100, but numbers $0-100$ were visible by moving the mouse through the scale before clicking.

\section{STATISTICAL ANALYSIS}

Data were compared using analysis of variance (ANOVA).

\section{RESULTS}

The results are shown in Figure 2. This figure suggests that the strongest illusion of control was observed in the laboratory participants that were 

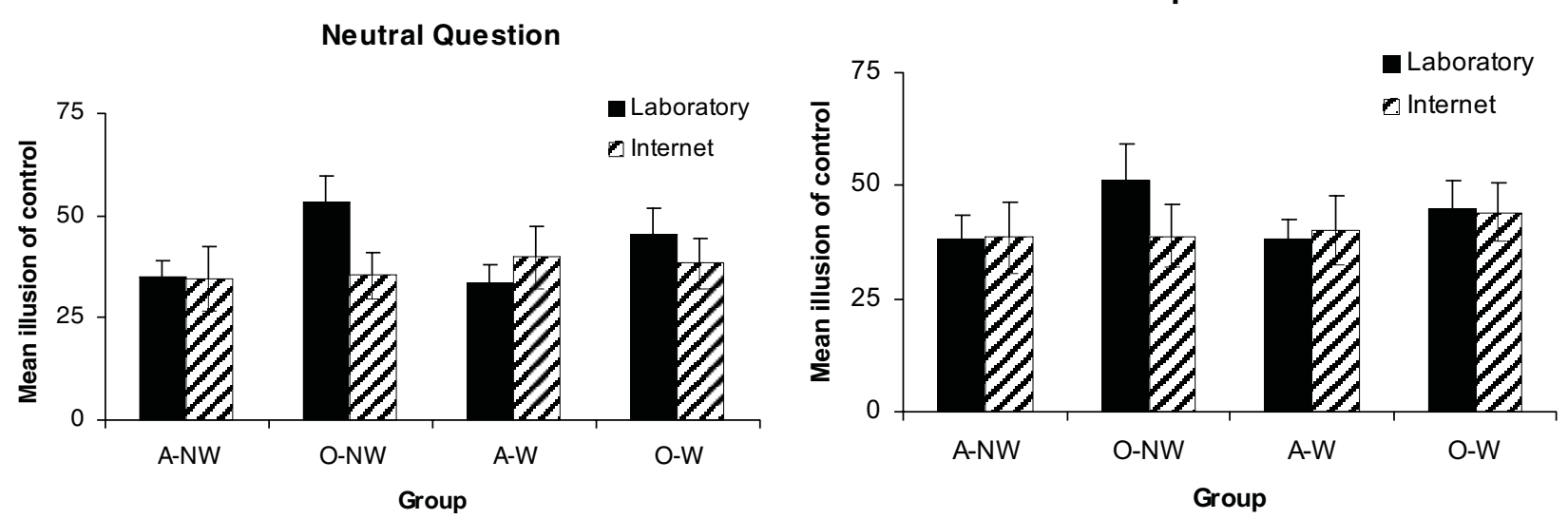

FIG. 2. Illusion of control shown by Internet and control (laboratory) participants. Groups W were warned at the start of the experiment that the flashes might be uncontrollable; groups NW were not warned. Groups O tried to obtain the flashes; groups A tried to avoid them. At the end of the experiment all participants were asked to rate to what degree they thought they had controlled the flashes (Neutral Question; left panel). Once they responded, they all were explicitly told that everything might have been preprogrammed and were asked to rate again the degree with which they, rather than the program, had controlled the flashes (Explicit Question; right panel). Under all conditions, participants showed a significant illusion of control. An offline version of the computer program used for this experiment, including instructions and test questions, can be downloaded from http://paginaspersonales.deusto.es/ matute/soft/flashes.zip.

trying to obtain the flashes and that had not been warned at the start of the experiment that the flashes might be uncontrollable. However, a strong illusion of control was observed even among those who were warned and even when they responded to the explicit question. Two 2 (Warned vs. Non Warned) $\times 2$ (Obtain vs. Avoid) $\times 2$ (Laboratory vs. Internet users) analyses of variance conducted separately on the responses to the neutral and the explicit question showed no main effects or interactions (all $p>0.05$ ), suggesting that all conditions yielded had a similar degree of illusion of control. Most importantly, under all conditions did the Laboratory and the Internet participants show a belief of control that was significantly different from 0 (all $p<0.001$ ). This is important because the actual control that was possible over the flashes was 0: The flashes were equally likely to occur regardless of whether or not the subject responded.

\section{DISCUSSION}

Both the laboratory and the Internet participants developed the illusion that they were controlling the flashes that were being presented in the computer screen. Interestingly, if this occurs in such a simple (and irrelevant for survival) situation as the one we have tested here, it is not strange that it occurs when people are confronted with more important life events that occur independently of their behavior such as, for example, health improvements. Indeed, the most important point that the present results show is that the tendency to develop an illusion of control is much stronger than we generally assume. No matter whether participants were warned at the start of the experiment that they might have no control; no matter whether the second question that they were asked was explicit about the possibility that everything had been preprogrammed. Both laboratory and Internet participants responded as if they had had a considerable degree of control over the flashes and were reluctant to accept that the outcome had occurred independently of their behavior. If they had tested for the probability of the outcome in the absence of responding they would have known that the outcome was not being produced by their responding. But as previously mentioned, the problem is that this is something that people do not test by default.

The fact that the illusion of control is related, among other things, to a high probability of responding, suggests that it might be the result of a good strategy for survival: If there is just a single little chance to obtain an important event, people who persist in responding once and again and again no matter what others say, do surely have many more opportunities for survival than those that become passive and do nothing to obtain what they want. 
The collateral effect is, of course, that if they respond all the time and reinforcement occurs with high frequency, then they have no way to know that the outcome would have occurred with the same probability if they had not responded: An illusion of control is therefore quite likely to develop as a secondary effect. Although the illusion of control is an irrational belief, it might have evolved as a consequence of a general adaptive strategy.

But even so, there is no doubt that there are also many natural conditions in which being able to reduce the illusion of control might be important and mental health professionals should be prepared to reduce these illusions when necessary. As an example, it could be quite devastating for a patient to assume that a given magical herb is controlling an illness that could be easily cured if the patient went to the hospital instead of taking the herb. Thus, analyzing the conditions that can reduce the illusion of control may often prove important.

Several conditions have been shown to reduce the illusion of control. For example, a very long exposure to the uncontrollable outcome reduces the illusion of control. ${ }^{10}$ If we had used 500 rather than 50 trials we probably had been able to reduce the illusion of control. Also, a very low outcome probability can reduce the illusion of control.2,6,12 For example, if someone's health never improves, sooner or later this person will abandon the superstitious rituals. And using very short intertrial intervals is also known to reduce the effect. ${ }^{18}$ Unfortunately, however, knowing that all these variables can reduce the illusion of control do not help us much in reducing the illusion of control that takes part in every day, natural settings. In natural superstitious settings there is often no time for such long exposures; and there is often no way in which the therapist can manipulate variables such as the number of trials, the outcome's density, or the intertrial intervals. However, there is at least one variable that is certainly in the therapist's (and the experimenter's) side and that can be used to reduce the illusion of control. This is information: Informing and explaining people very explicitly that the only way they have to learn whether or not they have control is to test both what happens when they perform the response as well as what happens when they do not respond, has been shown to reduce superstitions and illusions of control not only in many laboratory experiments, $, 10,11$ but most importantly, through the history of humankind. After all, providing this type of information is equivalent to showing people the basic principles of scientific thinking.

\section{ACKNOWLEDGMENTS}

We thank Raúl Bárcena for his invaluable help in adapting the computer program for this experiment. This research was supported by Junta de Andalucía (Grant SEJ-406).

\section{REFERENCES}

1. Langer, E.J. (1975). The illusion of control. Lournal of Personality and Social Psychology 32:311-328.

2. Alloy, L.B., \& Abramson, L.Y. (1979). Judgment of contingency in depressed and nondepressed students: Sadder but wiser? Iournal of Experimental Psychology: General 108:441-485.

3. Matute, H. (1994). Learned helplessness and superstitious behavior as opposite effects of uncontrollable reinforcement in humans. Learning and Motivation 25: 216-232.

4. Allan, L.G. (1980). A note on measurement of contingency between two binary variables in judgment tasks. Bulletin of the Psychonomic Society 15:147-149.

5. Aeschleman, S.R., Rosen, C.C., \& Williams, M.R. (2002). The effect of non-contingent negative and positive reinforcement operations on the acquisition of superstitious behaviors. Behavioural Processes 61:37-45.

6. Matute, H. (1995). Human reactions to uncontrollable outcomes: further evidence for superstitions rather than helplessness. Quarterly Journal of Experimental Psychology 48B:142-157.

7. Alloy, L.B., \& Clements, C.M. (1992). Illusion of control: Invulnerability to negative affect and depressive symptoms after laboratory and natural stressors. Journal of Abnormal Psychology 101:234-245.

8. Matute, H. (1996). Illusion of control. Detecting response-outcome independence in analytic but not in naturalistic conditions. Psychological Science 7:289-293.

9. Skinner, E.A. (1985). Action, control judgments, and the structure of control experience. Psychological Review 92:39-58.

10. Shanks, D.R., \& Dickinson, A. (1987). Associative accounts of causality judgment. In: G.H. Bower (ed.), The psychology of learning and motivation. Vol. 21. San Diego, CA: Academic Press, pp. 229-261.

11. Wasserman, E.A. (1990). Detecting responseoutcome relations: toward an understanding of the causal texture of the environment. In: G.H. Bower (ed.), The psychology of learning and motivation. Vol. 26. San Diego, CA: Academic Press, pp. 27-82.

12. Allan, L.G., Siegel, S., \& Hannah, S. (2007). The sad truth about depressive realism. Quarterly Journal of Experimental Psychology 60:482-495.

13. Bandura, A. (1977). Self-efficacy: toward a unifying theory of behavioral change. Psychological Review 84:191-215.

14. Crocker, J. (1981). Judgment of covariation by social perceivers. Psychological Bulletin 90:272-292. 
15. Frankel, M.S., \& Siang, S. (1999). Ethical and legal aspects of human subjects research on the Internet. Report of a workshop convened by the American Association for the Advancement of Science, Program on Scientific Freedom, Responsibility, and Law, Washington, D.C. Available at: www.aaas.org/spp/ dspp/sfrl/projects/intres/main.htm. Accessed May 6, 2005.

16. Matute, H., Vadillo, M.A., \& Bárcena, R. (2007). Webbased experiment control software for research and teaching on human learning. Behavior Research Methods (in press).

17. Vadillo, M.A., Bárcena, R., \& Matute, H. (2006). The internet as a research tool in the study of associative learning: an example from overshadowing. Behavioural Processes 73:36-40.

18. Msetfi, R.M., Murphy, R.A., \& Simpson, J. (2007). Depressive realism and the effect of inter-trial-interval on judgements of zero, positive and negative contingencies. Quarterly Journal of Experimental Psychology 60:461-481.

19. Rescorla, R.A., \& Wagner, A.R. (1972). A theory of Pavlovian conditioning: variations in the effectiveness of reinforcement and nonreinforcement. In: A.H. Black \& W.F. Prokasy (eds.), Classical conditioning II: Current research and theory. New York: Appleton, pp. 64-99.

\author{
Address reprint requests to: \\ Dr. Helena Matute \\ Departamento de Psicología \\ Universidad de Deusto \\ Apartado 1, 48080 Bilbao, Spain
}

E-mail: matute@fice.deusto.es 